\title{
La mujer en la ventana: Una iconografía del XIX en pintura e ilustración
}

\author{
M. a Dolores BAstida de LA CALLE
}

La actitud historiográfica con respecto a la pintura del siglo XIX descansa en un prejuicio que impide, en cierta medida, una consideración críticamente objetiva. Aunque esta afirmación podría parecer una simplificación de la verdad, conviene recordar que el origen de aquella actitud es la profunda revolución en la apreciación estética que separa al siglo XIX del $x x$, revolución que concluiría en una general convicción de que las cualidades esenciales del arte residen en la forma ${ }^{1}$. En ocasiones la intensidad de esa convicción alcanza grados extremos; por ejemplo, sobre una de las más significativas manifestaciones iconográficas se ha llegado a decir —no sin cierta justificación- que «...el contenido temático de la Capilla Sixtina nos es menos evidente que la estructura de sus formas... Aquí las formas han acabado siendo, para nosotros, el principal contenido de la obra en un sentido literal... ${ }^{2}$. En cualquier caso, nuestra persistente indiferencia, sino hostilidad, frente al contenido temático de la pintura ha producido un clima muy desfavorable para el estudio de la iconografía del $X I X$, un periodo durante el cual, para lo mejor y para lo peor, el pintor habia concertado un gran pacto con la literatura, pacto del que surgen expresiones como «literatura pintada» o "pintores poetas".

Para el artista del siglo xIX el tema podía poseer significado estético, y por ello dedicó aquél gran parte de su interés a la búsqueda y a la interpretación de variantes temáticas. Durante una larga secuencia de siglos la iconografía había sido fijada de una manera invariable por un rígido marco religioso impregnado con referencias mitológicas y, en los dos siglos que

\footnotetext{
'EITNER, Lorenz, «The Open Window and The Storm-Tossed Boat: An Essay in The Iconography of Romanticism", en Art Bulletin, vol. XXXVIl, diciembre (1955), pp. 279-290.

2 SChAPIRO, Meyer, Theory and Philosophy of Art: Style, Artist, and Society. New York, George Braziller, 1994, p. 45.
} 
precedieron al $\mathrm{x} \mathrm{Ix}$, por la masiva propaganda de monarcas y estados. Ahora, como consecuencia de los cambios producidos en la sociedad, en particular la aparición de una clase media educada que proporcionaba una audiencia muy distante del Antiguo Régimen, el artista se sentía empujado a mostrar originalidad en la elección de temas.

Por otra parte, el carácter liberador de las transformaciones sociales que conformaron el siglo XIX permitía una diversificación sin trabas en la creación y la manifestación artísticas. Ignorada la herencia de la rígida iconografía tradicional, el artista se esforzó en la expresión romántica de significados personales, lo que condujo al interés por un lenguaje simbólico de alusiones múltiples e imágenes vagamente evocadoras. El caso puntual que aquí nos interesa, el tema de la Mujer en la Ventana, corresponde a uno de esos abiertos simbolismos de la iconografía moderna que sugieren significados inexperados y cuyo origen no puede encontrarse en una fuente única.

Es en el primer cuarto de siglo xix cuando aparece la figura de la mujer en la ventana como un motivo iconográfico favorito. Existen naturalmente antecedentes parciales de ese motivo, por una parte en ciertos mensajes que ya el Renacimiento italiano, y el arte Flamenco, habían utilizado para dibujar un aspecto crucial del ideal femenino: el estado de inocencia sexual anterior al matrimonio consumado. La ventana, como metáfora que definía a la mujer, como signo de contención, reiteraba el carácter de interior de un espacio femenino preservado de luchas y confusiones en el mundo exterior. Ejemplos de pintura renacentista del siglo xV — Las Anunciaciones de Fra Angélico, Filippino Lippi, Lorenzo di Credi-, o de pintura flamenca -Díptico con la Anunciación de Petrus Christus, La Anunciación de Roger Van Der Weyden-, simbolizan todos ellos el estado de virginidad de María, la santidad del espacio que garantizaba su pureza y justificaba su elección entre las mujeres para llegar a ser Madre de Dios ${ }^{3}$. De hecho, es posible encontrar este icono religioso, trasferido al cercano presente del xIX y motivado por un revival católico, en una obra de Maurice Denis, Misterio Católico (fig. 1), que sitúa la escena en una moderna habitación en la que el árigel Gabriel es representado por un sacerdote con misal abierto y precedido por dos monaguillos con candelabros.

La iconografía de la mujer en là ventana asumió, asimismo, préstamos de la tradición pictórica holandesa del siglo xVII - Visita del oficial de Jan Vermeer, Madre e hija pelando manzanas de Pieter de Hooch-, que en-

3 Higonnet, Anne, Berthe Morisot's. Images of Women. Cambridge, Harvard University Press, 1994, p. 72. 


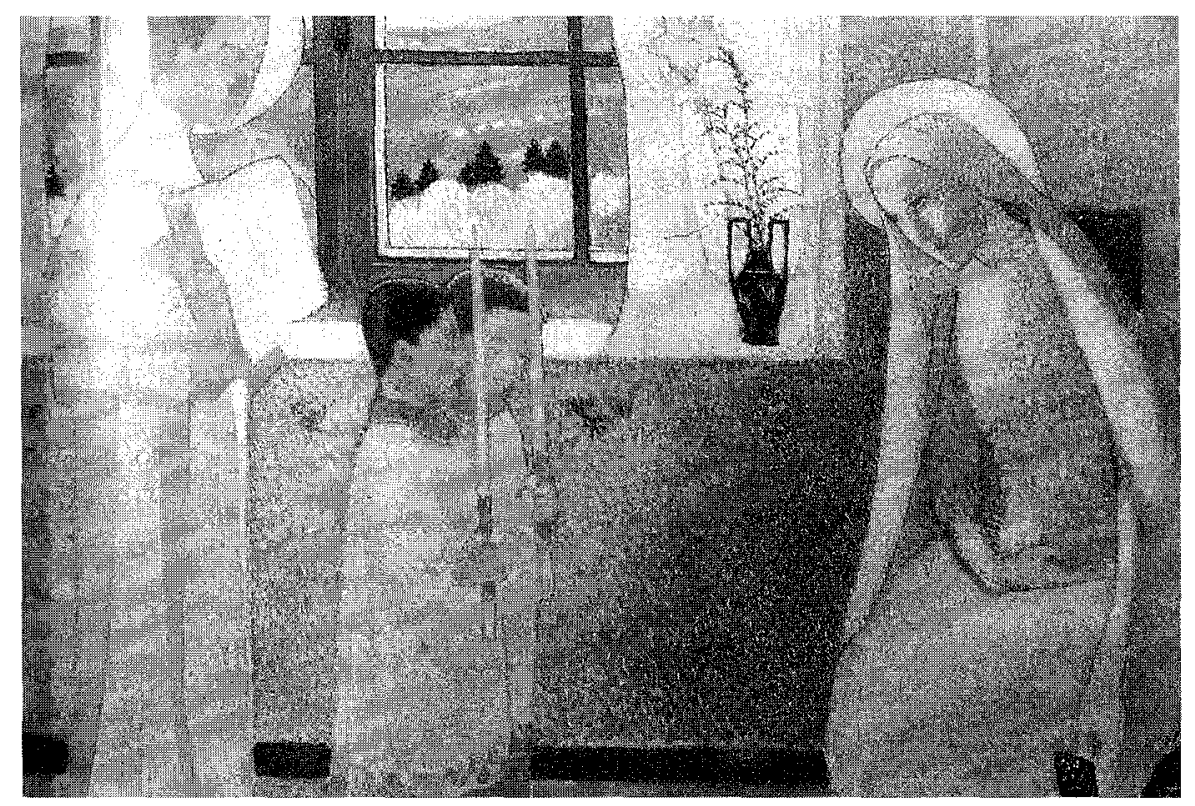

Fig. 1. Misterio Católico. Maurice Denis, 1890.

lazaría con la vena francesa del Intimismo que discurre desde Chardin (Cuatro escenas domésticas) en el siglo XVIII, a Bonnard, Vuillard o Matisse en la transición del XIX al XX. En todas ellas es evidente la instauración del tipo de vida de clase media: los artistas registran mujeres que parecen encontrar placer en escenas domésticas, a las que agrada un interior confortable. Un mundo de mujeres dispuesto para ver el mundo a través de la ventana, un paradigma de marco dentro del marco ${ }^{4}$.

Pero, frente a este perfil iconográfico de mujer que acepta las tareas realizadas en la domesticidad, el «hogar», en cuyo interior la ventana no va más allá de sẹvir como foco de luz, surge en el siglo XIX una imagen de mujer y ventana que refleja una emoción nueva, que arranca, sin duda, de Caspar David Friedrich, en Mujer mirando por la ventana de su estudio, 1822 (fig. 2), y se cierra pasado un siglo en Figura en una ventana (fig. 3) de Salvador Dalí, ya entrado el xx (1925).

4 Gállego, Julián, El cuadro dentro del cuadro. Madrid, Cátedra, 1978, p. 87. 
M. DOLORES BASTIDA DE LA CALLE

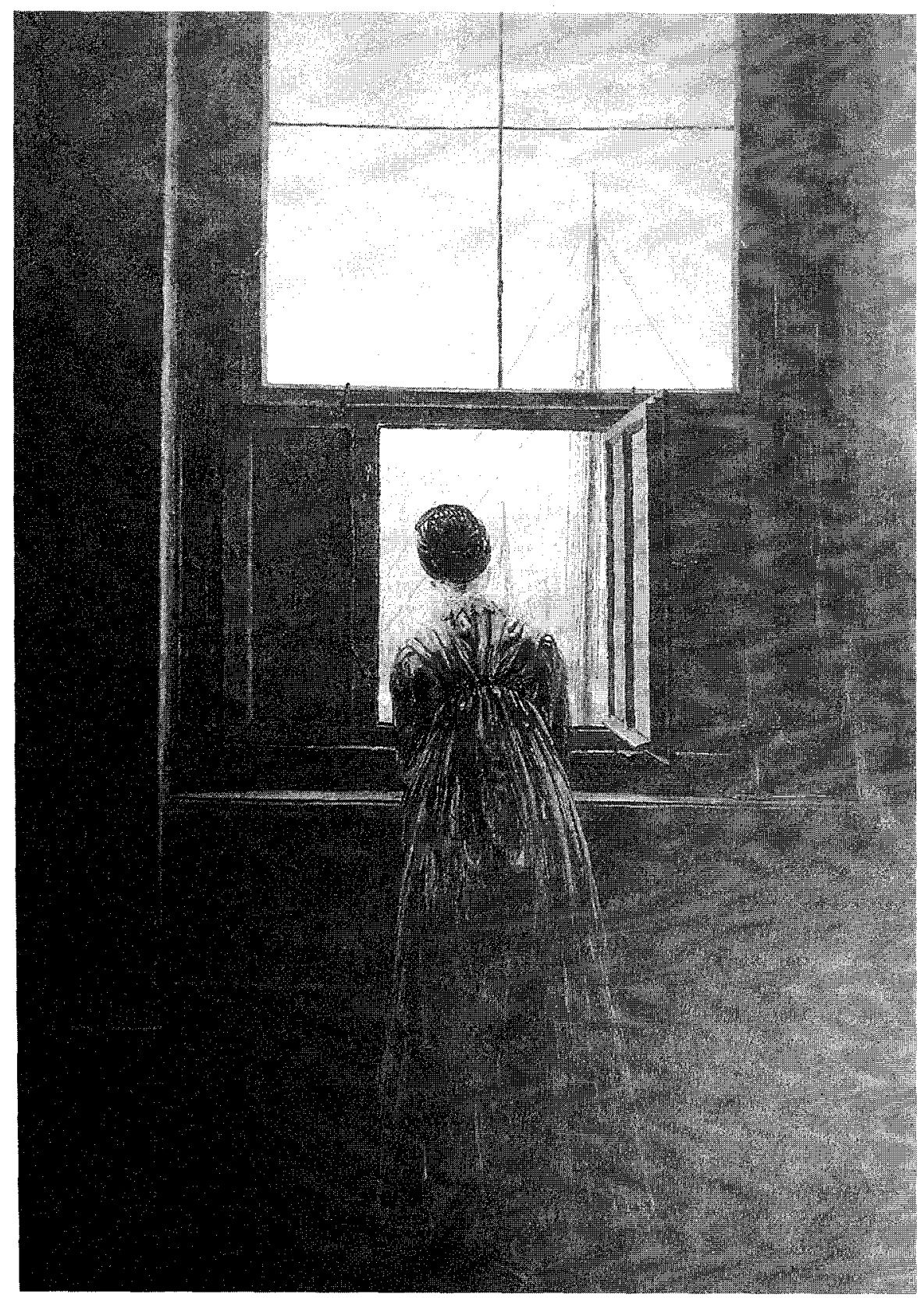

Fig. 2. Mujer mirando por la ventana. Caspar David Friedrich, 1822. 


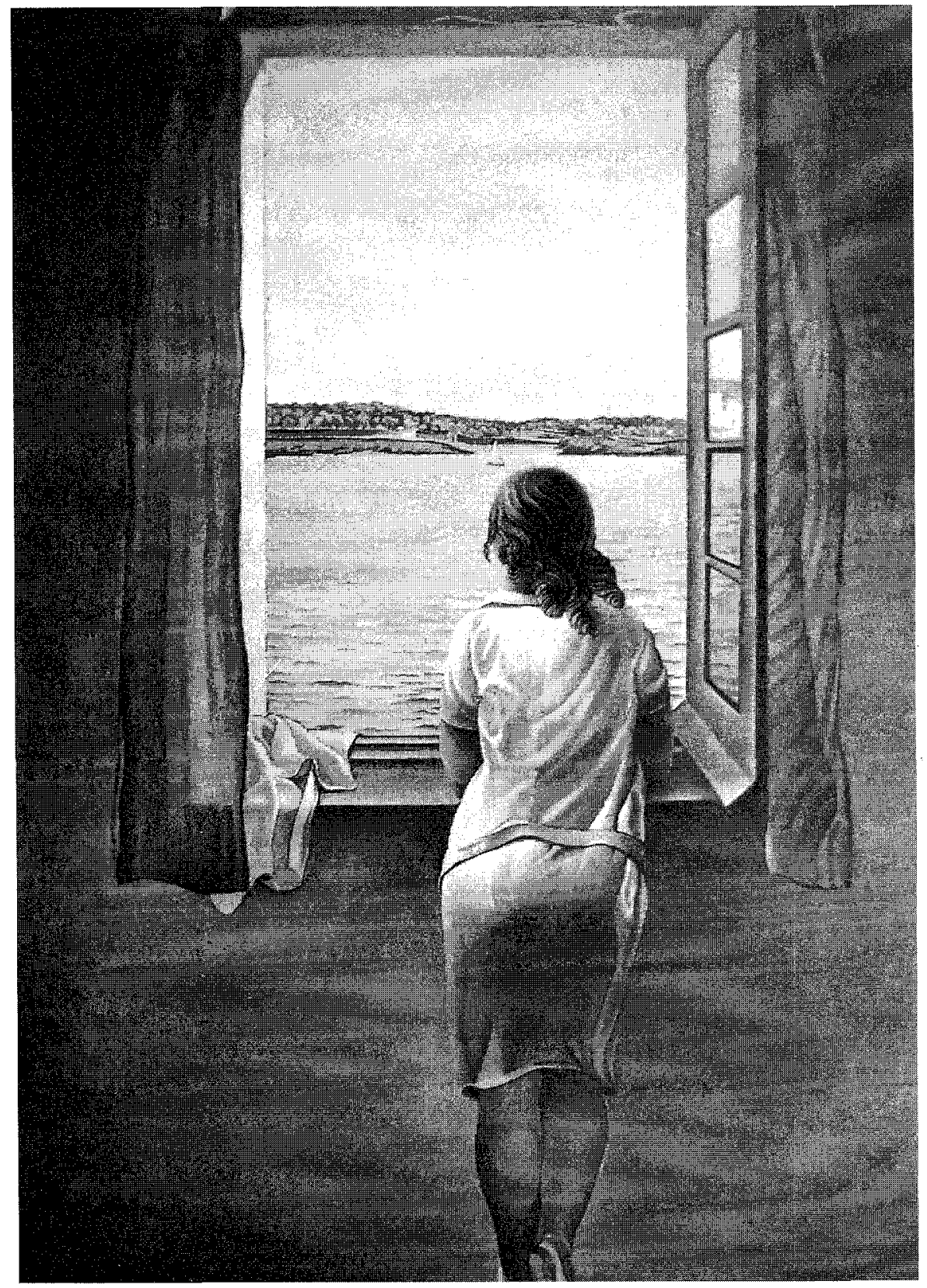

Fig. 3. Figura en una ventana. Salvador Dalí, 1925. 
Aunque se está aquí en presencia de iconos que no ocultan la fuerza de los "géneros» holandés, y francés del XVIII, se nos presenta ciertamente algo nuevo. En el cuadro de Friedrich, o en uno similar del pintor danés Vilhelm Hammershoi, Interior (1890), las imágenes están teñidas de un sentido romántico y cargadas del particular repertorio de motivos del Romanticismo. En Friedrich, la vista del mástil de un barco, en la cima, nos evoca tanto una imagen poética de misterio -el infinito religioso de la niebla nórdica-, como la lejanía del viaje hacia lo desconocido ó el símbolo de la nave del destino humano. En la Figura de Dalí, la feliz domesticidad de una muchacha en tareas cotidianas -Dalí había comunicado a García Lorca que soñaba con imitar a los holandeses ${ }^{5}$, y en su pintura realista de los años 1925-1927 parece haber sido influido por Vermeer ${ }^{6}$ - coexiste con la complacencia ante la profunda perspectiva de un exterior sensual, un infinito de mar y cielo mediterráneos. De modo similar, en un óleo de Moritz Von Schwind, Hora de la Mañana (1858), la muchacha que interrumpe su tarea doméstica, asomándose a la ventana, parece complacida por la observación de unas montañas y un cielo soleados.

Es interesante observar que el tema de la mujer en la ventana aparece repetidamente en el rico mundo de la ilustración gráfica de la mitad del XIX. Una estampa de 1837, Zenobia (fig. 4), basada en un cuadro de William Pickersgill y ambientada en un tema oriental, evoca, como en Friedrich, el deseo de huida de un recinto interior hacia un espacio de cielo y mar sin límites. En el lenguaje romántico fue usual establecer una dialéctica entre lo próximo y lo lejano, lo finito y lo infinito, un reflejo, quizás, de la inquietante percepción romántica del enfrentamiento entre individuo y universo ${ }^{7}$. En el romanticismo, por otra parte, como señala Erik Forssman, la figura que nos vuelve la espalda pretende expresar un anhelo por la naturaleza, una liberación de los lazos terrenales, o un general deseo insatisfecho ${ }^{8}$.

En las publicaciones gráficas de la época se descubren asimismo numerosas estampas de ilustración literaria, estampas usualmente xilográficas, que enriquecen la profundidad de los variados significados del tema. En una edición de E. Moxon de los Poemas de Lord Tennyson (1857), los hermanos

5 BozaL, Valeriano, Pintura y Escultura Españolas del siglo xx (1900-1939). Summa Artis, vol. XXXVI. Madrid, Espasa Calpe, 1992, p. 474.

6400 Obres de Salvador Dalí del 1914 al 1983. Barcelona, Exposició realitzada conjuntamente per la Generalitat de Catalunya i el Ministeri de Cultura en homenatge a Salvador Dalí, vol. I, p. 64.

7 Rosemblum, Robert, Modern Painting and the Northern Romantic Tradition. Friedrich to Rothko. Londres, Thames and Hudson, 1994, p. 62.

\& WiELAND, Schmied, Friedrich. Nueva York, H.N. Abrams, 1995. 


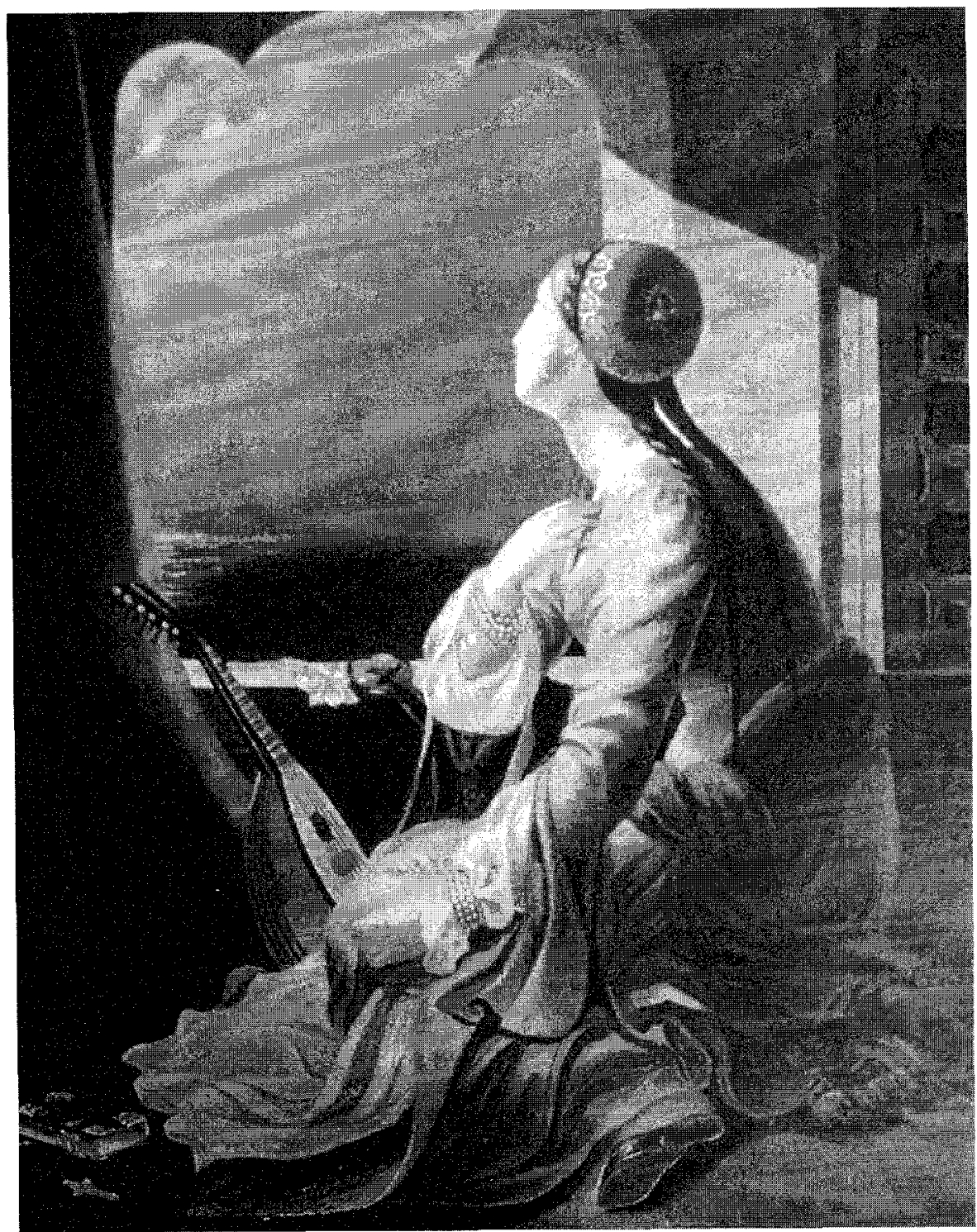

Fig. 4. Zenobia. William Pickersgill, en Cabinet of paintings, 1837. 
Dalziels grabaron una ilustración del Pre-Rafaelista John Everett Millais sobre el poema St. Agnes'Eve (fig. 5). Tennyson describía los anhelos de pureza de una monja asomada a una ventana de su convento en una noche de nieve y estrellas, aunque en esta delicada estampa, el ensueño de la muchacha parece ir más allá del sentimiento religioso, una interpretación deformada del poema que se repite en ciertas ilustraciones de Dante Gabriel Rosetti para el mismo libro. Millais ya había visualizado a una dama ante un ventanal gótico en un cuadro de 1851, Mariana, basado en otro poema de Tennyson.

En una ilustración para Count Burkhardt (fig. 6), publicada en la revista Once a Week (1862), James McN. Whistler nos presenta a una monja en actitud reflexiva, con la cabeza inclinada y la mirada perdida sobre la ciudad muerta. En la estampa, que apunta un rasgo distintivo de las escasas xilografias de Whistler -el uso de largas líneas, finas y abocetadas, que recuerdan un aguafuerte-, aparece la ventana como un lugar de indefinición entre espacios, que invita a la mirada a vagar en la lejanía. Esa actitud reflexiva de la mujer se encuentra asimismo en otros grabados, como Thinking and Wishing de Charles Green (fig. 7), aparecida en The Churchman's Family Magazine en 1864, o Wives and Daughters (fig. 8), sobre una novela de Mrs. Gaskell publicada por entregas en The Cornhill Magazine en ese mismo año, estampa que muestra la riqueza y delicadeza de los dibujos de la primitiva y mejor época de George du Maurier.

En una primera comparación de estas ilustraciones con los cuadros de Friedrich y Hammershoi, sería apropiado recordar la observación de Roger Fry sobre el carácter clásico o romántico de una obra de arte: «A mi juicio, una obra de arte es romántica si su efecto estético resulta de una asociación de ideas que se suscita en la mente del espectador. Una obra de arte es clásica si, para provocar la emoción, depende de su propia organización formal». Es claro que las ilustraciones literarias (figs. 4-8), cuyo contenido temático conoce previamente el espectador por la lectura de una narración que discurre en el tiempo, permiten, por su propia naturaleza, una abstracción, una paráfrasis de la realidad, que eliminan lo no esencial, y configuran así un medio romántico de expresión basado en alusiones evocadoras ${ }^{9}$.

Los elementos romántico y ciásico se superponen, por el contrario, en la Mujer en la Ventana de Friedrich o en el Interior de Hammershoi, al ser

\footnotetext{
- Existió, naturalmente, una ilustración gráfica no literaria cuyo máximo ejemplo fue la ilustración de noticia, que en ocasiones era detalladamente descriptiva, con un meticuloso realismo de fotografia.
} 
La mujer en la ventana: Una iconografia del XIX en pintura e ilustración

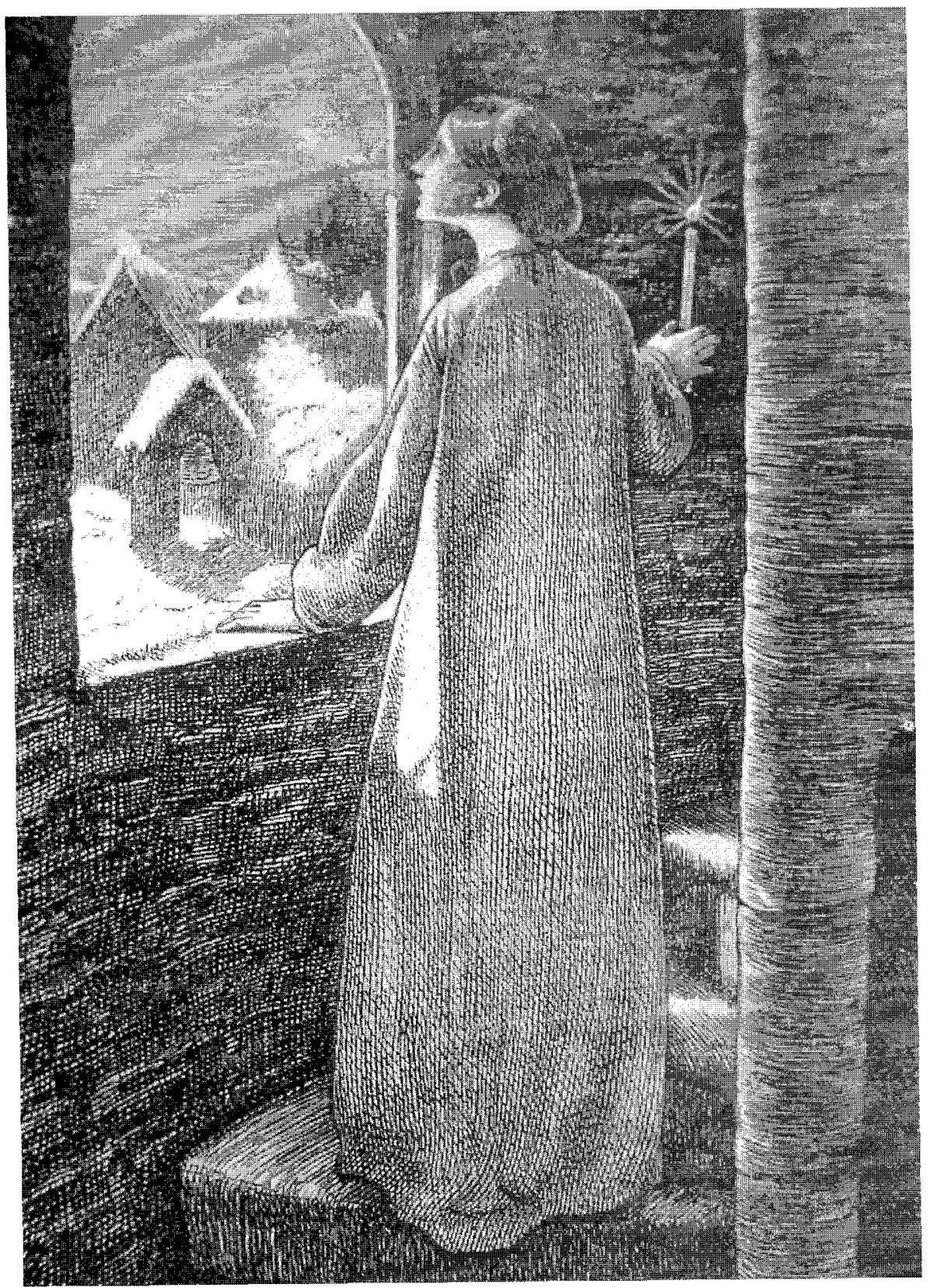

Fig. 5. St. Agnes'Eve. J. Everett Millais, en Poems de Lord Tennyson, 1857. 


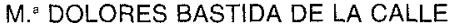

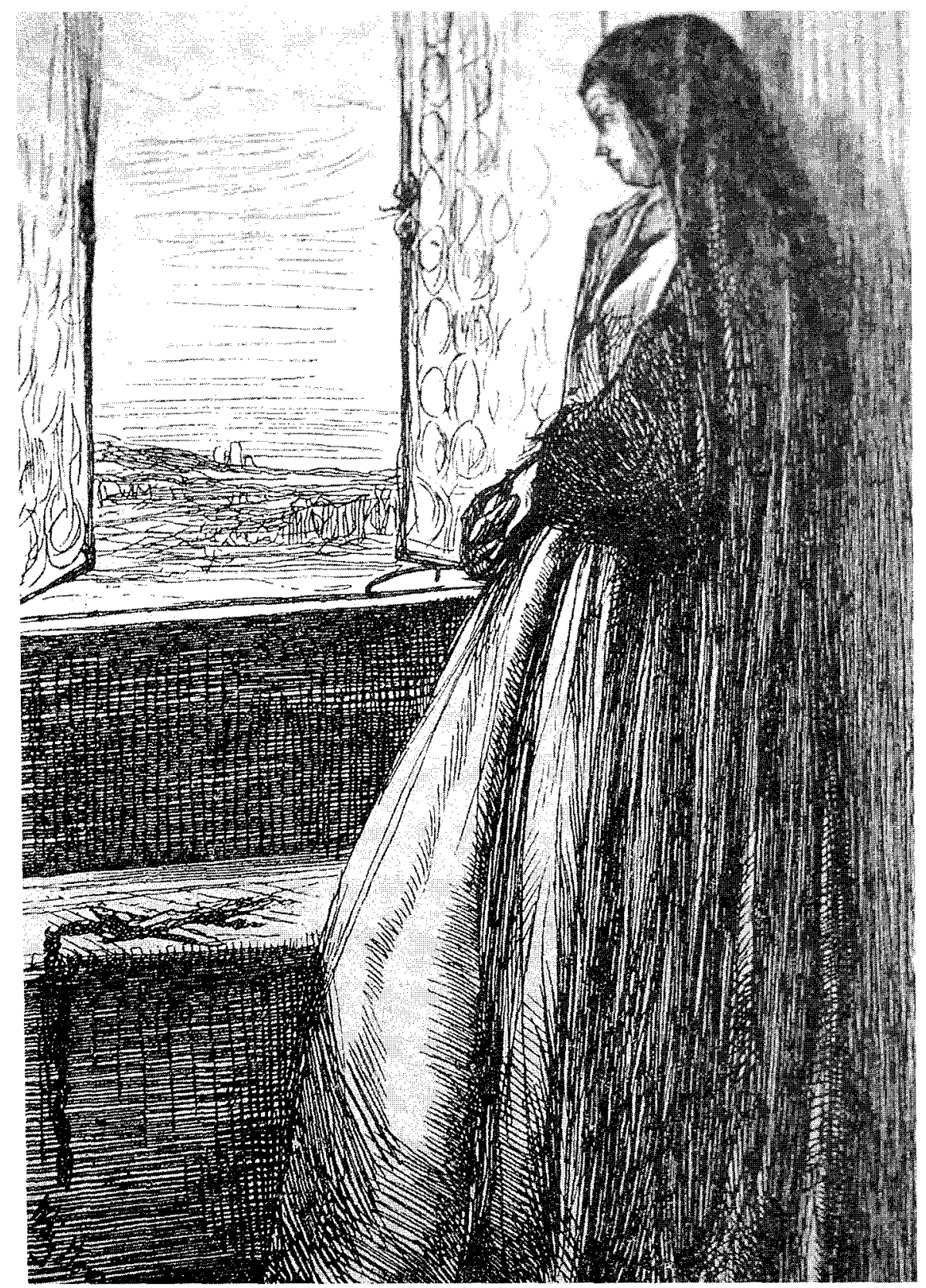

Fig. 6. Count Burkhardt. James McN. Whistler, Once a Week, 1862. 
La mujer en la ventana: Una iconografía del XIX en pintura e ilustración

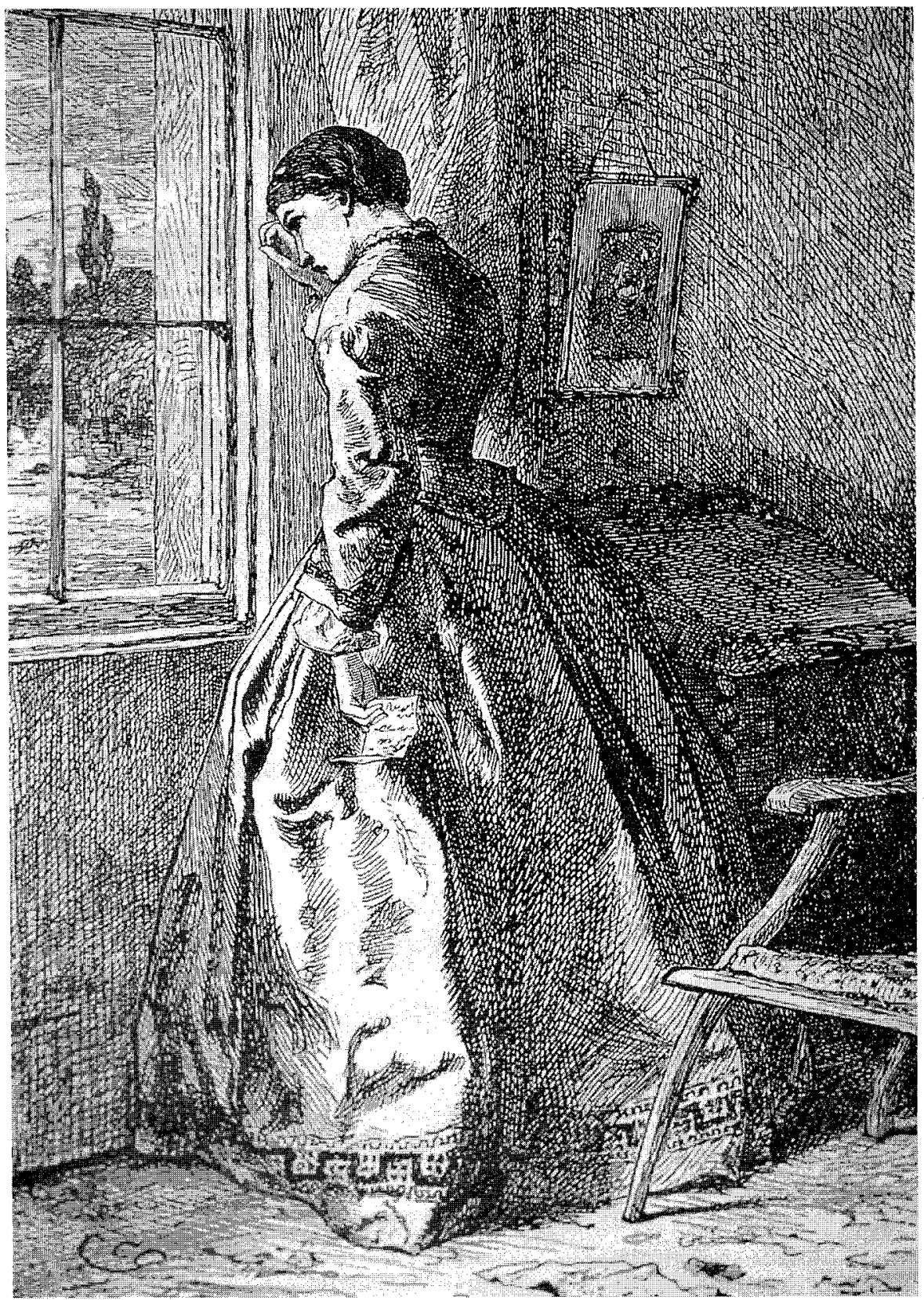

Fig. 7. Thinking and Wishing. Charles Green, The Churchman's Family Magazine, 1864. 


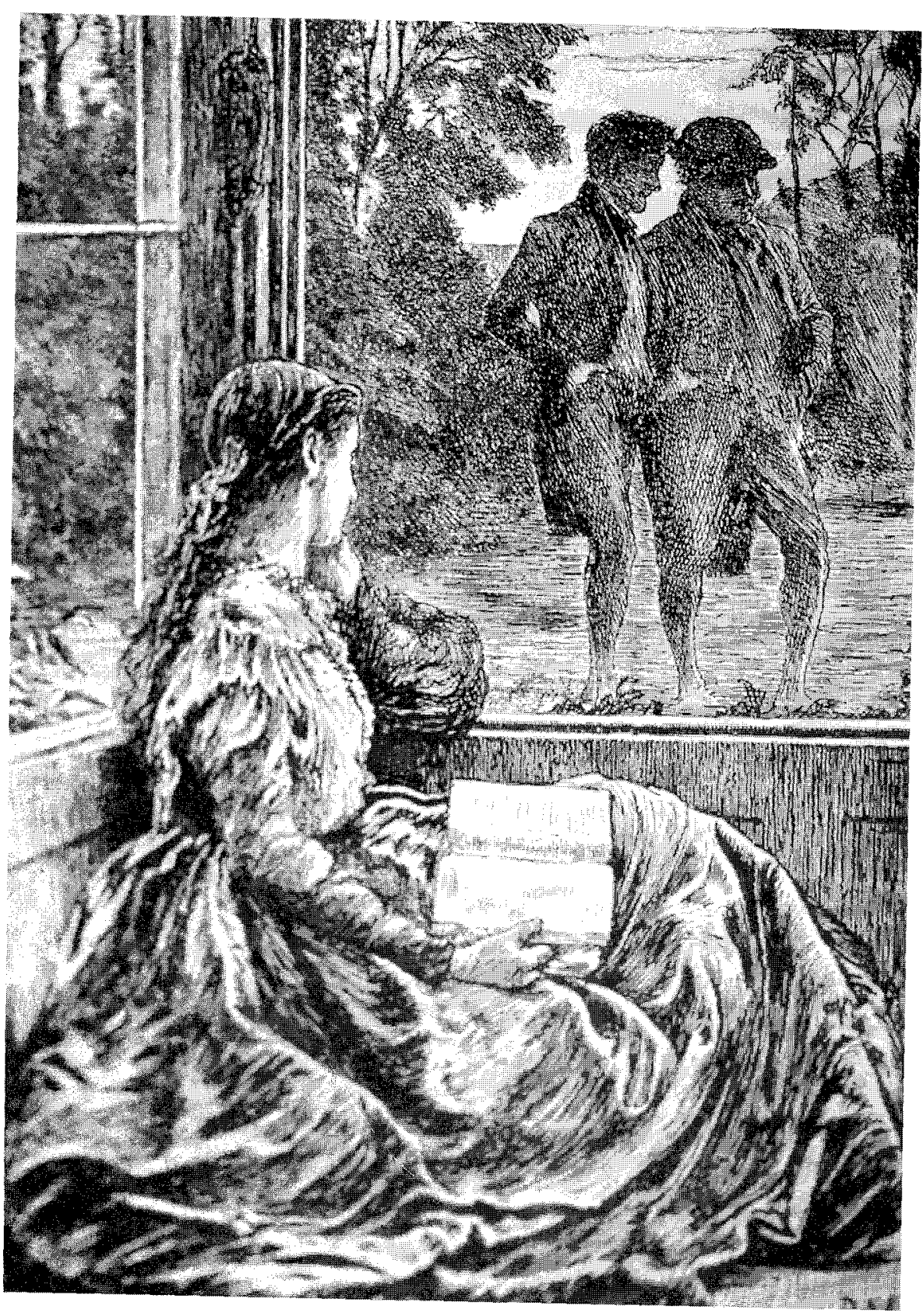

Fig. 8. Wives and Daughters. George Du Maurier, The Cornhill Magazine, 1864. 
ingredientes esenciales de su contenido estético los aspectos formales de la composición, como también ocurre en la Figura de Dalí. En estos cuadros la mujer se nos muestra encerrada en el marco de la ventana, marco que comunica los espacios interior y exterior, pero que paradójicamente utiliza ahora el artista para crear un tercer recinto, interior, cerrado, plano, en el que queda atrapada la figura. En las ilustraciones, sin embargo, la mujer se muestra lateralmente retirada de la ventana, cuyo marco aparece como un umbral, un elemento espacial que suscita la vida interior, vida que el artista contextualiza en el naturalismo poético del XIX, que era esencialmente el espíritu de los sesenta ${ }^{10}$, el producto de una época y una sociedad que amaba la sugerencia poética.

Convendría observar, en este punto, que en las aproximaciones europeas a la imagen de la mujer, en esos cien años que van de Friedrich a Dalí, los espacios interiores se utilizaron de modo más general para aludir a un cierto modelo de femineidad. Al registrar esos interiores, los artistas obviaron a veces la ventana como parte del lenguaje visual femenino, o situaron a la mujer próxima, tan sólo, a aquella, como en una estampa de A. Montague Rivers, For valour (fig. 9), en The Illustrated London News (Christmas Number, 1915). En cualquier caso, el siglo XIX, en Francia, Inglaterra o Alemania, fue un momento de intensa concentración artística sobre el carácter femienino de los interiores, como lo habían sido el siglo XV en Italia y Flandes, ó el XVII en Holanda. Pero esta correlación es apenas una coincidencia; esos momentos aluden a facetas muy distintas de un fenómeno tan sólo parecido. Estampas como Thinking and Wishing (fig. 7) o Wives and Daughters (fig. 8) definen un concepto de femineidad histórica y socialmente específico: la femineidad de la sociedad urbana industrial, y en particular la femineidad burguesa.

Obsérvese, sin embargo, que estas imágenes no están al servicio de intenciones usualmente adscritas a esa femineidad. Las imágenes no muestran sus aspectos comerciales, tan vitales para el poder de la moda - hacia 1860, las revistas de moda experimentaron un crecimiento muy notable-, y raramente escenas con anécdota o narrativa; tan sólo realzan, sutilmente, la presencia de la mujer, en unos casos mostrando su rostro y en otros ocultándolo, pero haciendo sentir su presencia. Se asociaba este tipo de mujer con alguna actividad intelectual: pensar, leer, o quizás recrearse en ciertas fantasías de carácter social o sexual. Esa temática visual perpetuaba el concepto de una mujer que no delata su vida interior, la

10 REID, Foster, Illustrators of the Eighteen Sixties. Nueva York, Dover, 1975, p. 2. 


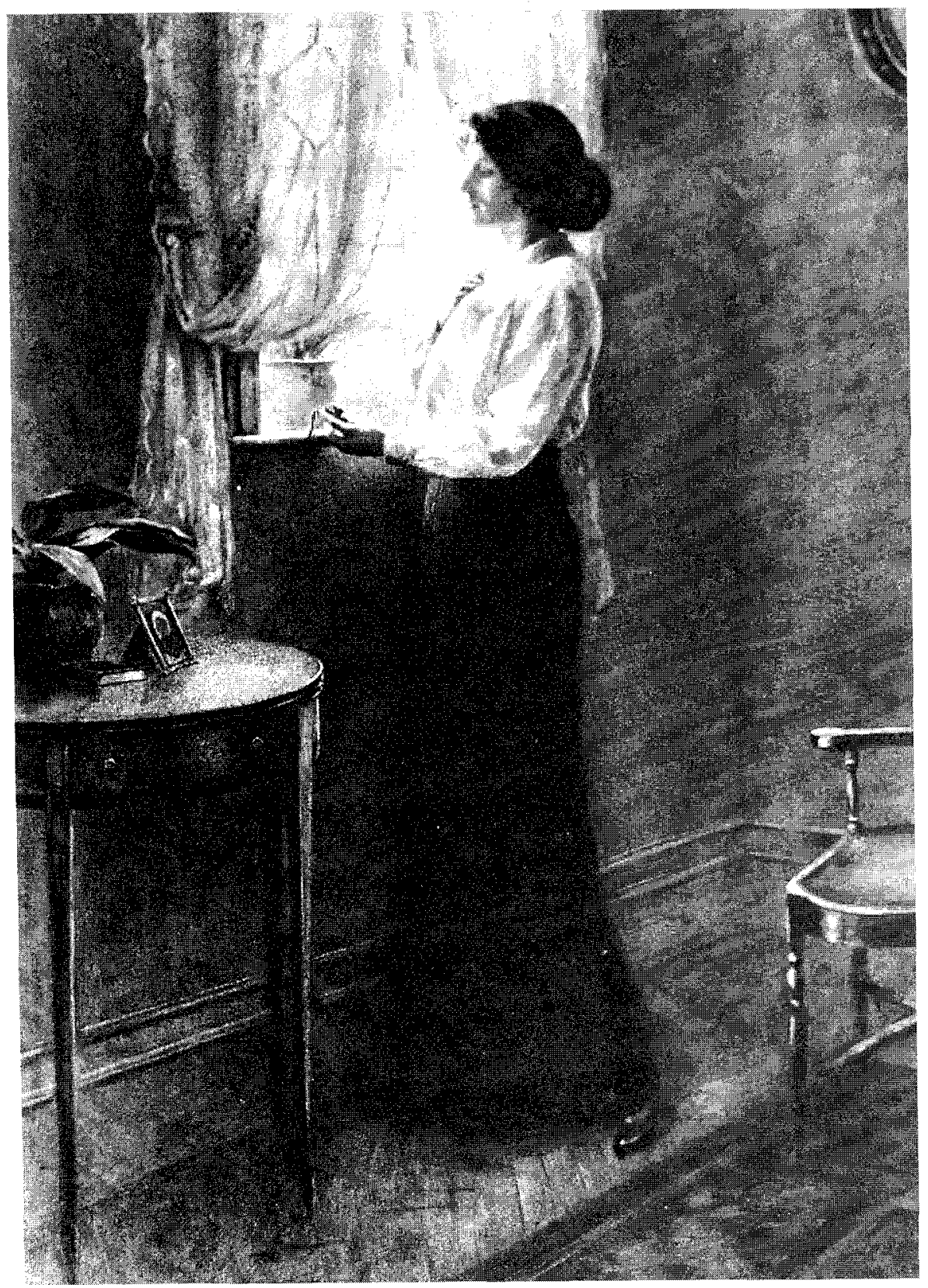

Fig. 9. For valour. A. Montague Rivers, The Illustrated London News, 1915. 
idea de la mujer como misterio y no como objeto de deleite visual. Raramente dicen nada estas figuras del momento en que han sido registradas, o muestran algún contacto sicológico con el espectador. No hay duda, sin embargo, que son mujeres absorbidas, en ocasiones en un momento de actividad interrumpida, como la costurera de Sólo un breve descanso (fig. 10), pintada por Anna Blunden en 1854. Aunque de mayor carga social, una estampa de T.A. Steinlen para una portada de Le Chambard Socialiste (Mayo 12, 1894), Les Joies de l'Été, (fig. 11), muestra, de manera muy similar, a una costurera inclinada sobre su tabla de trabajo, junto a la ventana, que asoma a un exterior de techumbres urbanas.

En la representación iconográfica que nos ocupa, la figura de la mujer aparece aislada en un esquema composicional plasmado en tres registros rígidamente separados: mujer, ventana, espacio exterior. Esta fría delimitación de iconos - una vista de lejanía, que en ocasiones evoca un paisaje $y$, en otras, horizontes vacíos o desolados; una figura concentrada en sí misma; un marco de ventana que actúa de límite, como los marcos de espejo o los bordes de sofá que gustaban de usar los impresionistas ${ }^{11}$ contribuye a pontenciar la tensión sicológica del cuadro. $Y$ esa tensión es máxima cuando se adivina en el espacio interior una relación frustrada, y la imagen resultante se transforma en una metáfora del aburrimiento ${ }^{12}$, el aburrimiento de una rnujer a la espera de algo nuevo, como en el cuadro Interior, Mujer en la Ventana (fig. 12), de Gustave Caillebotte (1880), o en la Mujer en la Ventana de Henry van de Velde (1890). Como señaló Edmund Duranty, coetáneo de los impresionistas, en su ensayo sobre La Nueva Pintura, «la ventana es un marco que está continuamente con nosotros durante el tiempo que estamos en casa, y ese tiempo es considerable» ${ }^{13}$.

Frente a los primitivos simbolismos de inocencia y virginidad, o la descripción complaciente de una domesticidad de interior, el tema de la mujer y la ventana exhibe en el siglo xIX una notable simbología más rica en significados y alusiones. Esa simbología va desde el anhelo del espacio exterior infinito o su aceptación complaciente (las contrapuestas poesías de deseo y posesión de A.G. Schlegel), hasta la utilización de la ventana

\footnotetext{
11 Higonnet, Anne, Op. cit., p. 72.

12 Distel, Anne; Druick, D.W.; Groom, G.; Rapetti, R. with J. Sagraves and K. Varnedoe. Gustave Caillebotte. Urban impressioniste (Exhibition Catalog). New York, The Art Institute of Chicago, 1995 , p. 144.

13 DURANTY, Louis Emile Edmond, “The New Painting: Concerning the Group of Artists Exhibiting at the Durant-Ruel Galleries" (1876), reimpreso en The New Painting: Impressionism 1874-1886. Seattle, University of Washington Press, 1986, pp. 37-49.
} 
M. ${ }^{a}$ DOLORES BASTIDA DE LA CALLE
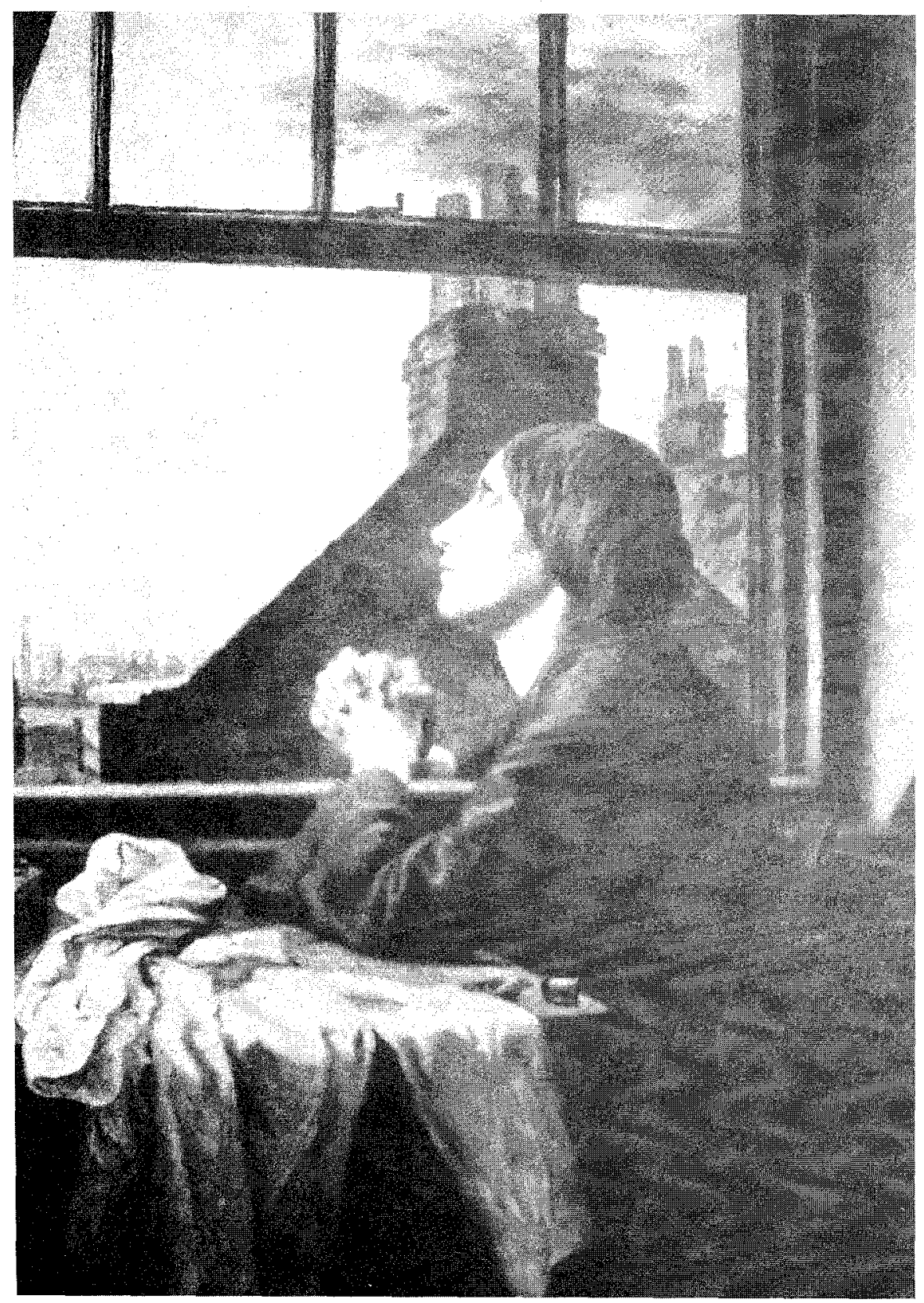

Fig. 10. Sólo un breve descanso. Anna Blunden, 1854. 


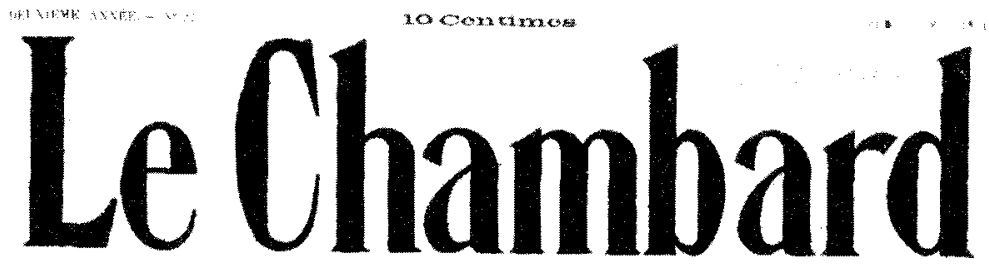

GURAT:

SOCLALINTI:

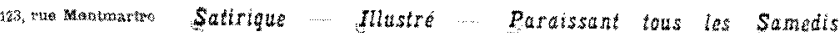

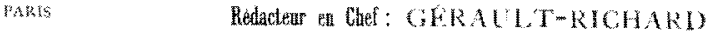

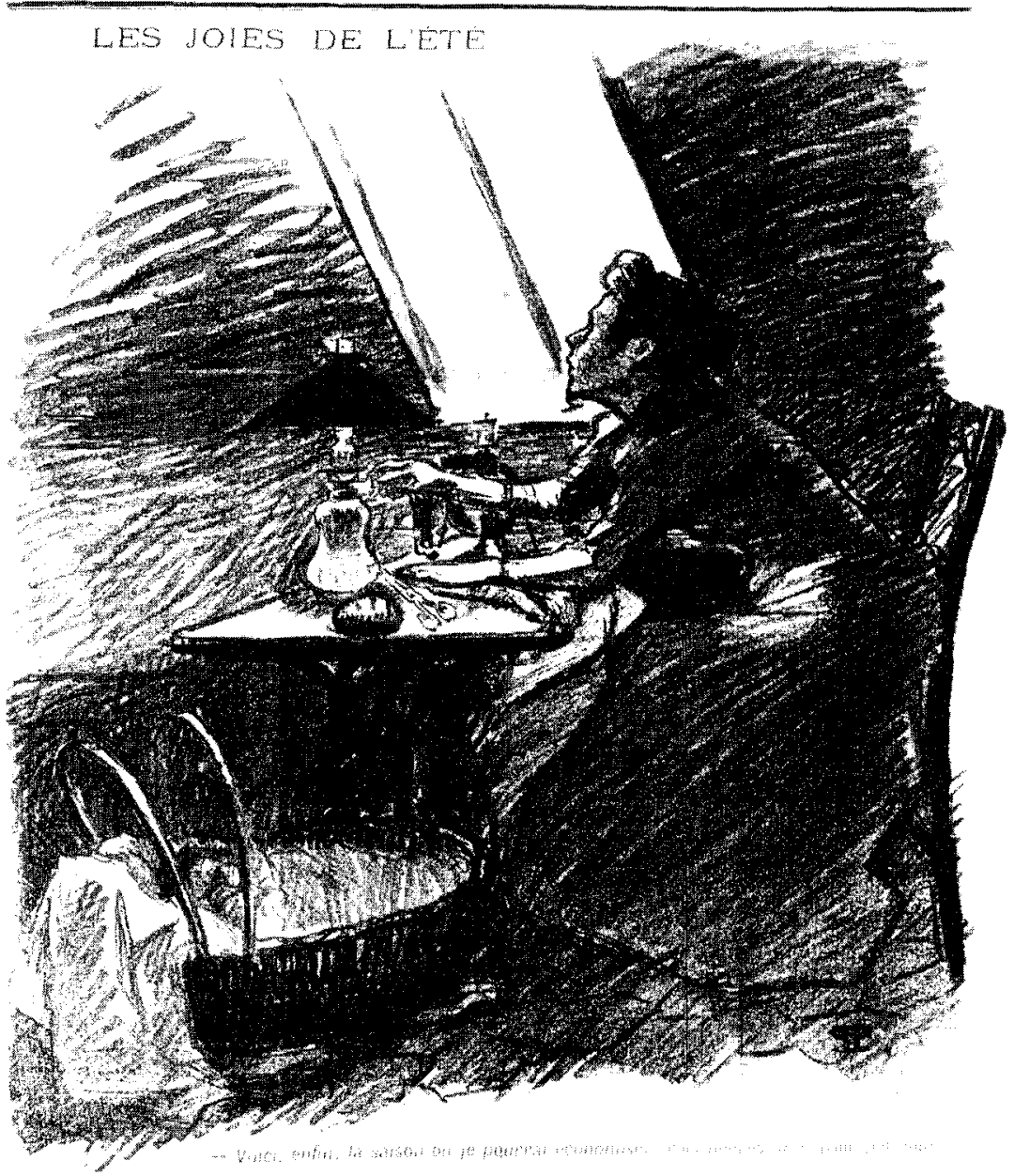

Fig. 11. Les Joies de l'Été. Théophile-Alexandre Steinlen, Le Chambord Socialiste, 1894. 


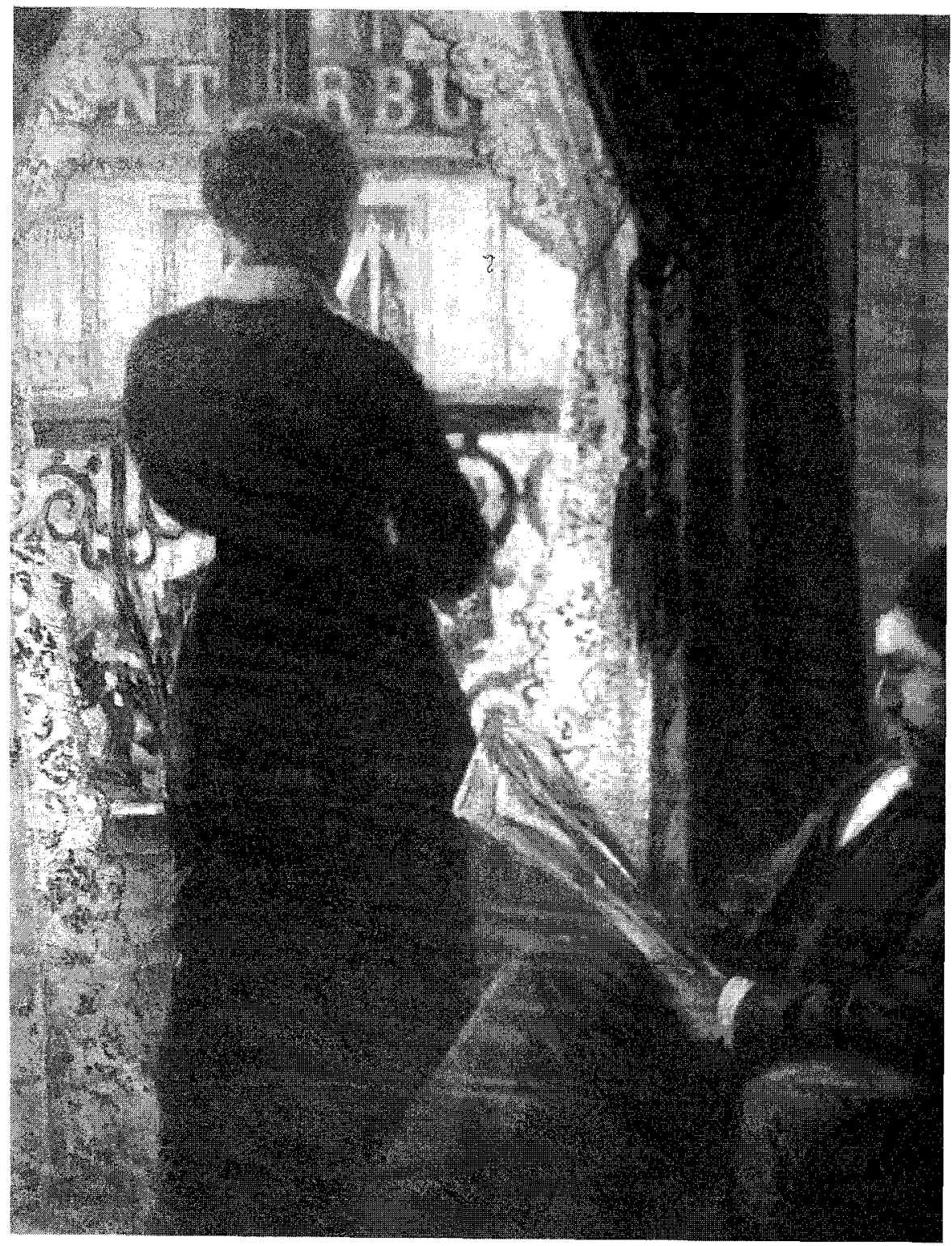

Fig. 12. Interior, Mujer en la Ventana. Gustave Caillebotte, 1880. 
como un elemento espacial que suscita una intensa vida interior en la mujer: divagación, reflexión, aburrimiento. Esa vida interior se enfatiza en la ilustración gráfica, que nos permite observar el rostro de la mujer, quien, por el contrario, se nos aparece usualmente de espaldas en la pintura, en una estilización formal que se añade al uso de la ventana como marco creador de un tercer espacio femenino. 
